\title{
34. MAGNETIC MINERALOGY OF BASALTS FROM LEG 49
}

\author{
K. Kobayashi, ${ }^{1}$ M. Steiner,${ }^{2}$ A. Faller,${ }^{3}$ T. Furuta,${ }^{1}$ T. Ishii, ${ }^{1}$ P. Shive,${ }^{2}$ and R. Day ${ }^{4}$
}

\section{INTRODUCTION}

The Curie temperatures and thermomagnetic behavior of the whole rocks, as well as the titanium content and microscopic features of titanomagnetite contained in the rocks, were studied on the same samples used for shipboard determinations of paleomagnetic properties. At least one (usually much more than one) sample was available from each lithologic unit of the basement rocks. A particular aim of the studies was to find any intersite variations of magnetochemical properties, such as variations with distance parallel to and perpendicular to the northern Mid-Atlantic and Reykjanes ridges. We also looked for variations with depth in the holes, such as might be caused by differences in magmatic differentiation or hydrothermal alteration. The major ferromagnetic phases, which are presumably responsible for the natural remanent magnetization and the marine magnetic anomalies, were carefully identified. The findings of the thermochemical magnetic study are correlated with rock magnetic and paleomagnetism results in the final chapter.

\section{THERMOMAGNETIC MEASUREMENT}

Changes in saturation magnetization $\left(\mathrm{J}_{\mathrm{s}}\right)$ with temperature (T) were studied on 120 samples from all the sites. The $\mathrm{J}_{\mathrm{s}}-\mathrm{T}$ curves were measured at the Ocean Research Institute, Tokyo (predominantly Holes 407 and 409 , indicated by $\mathrm{K}$ in the last column of Table 1) and at the University of Wyoming (mainly Holes 409, 410, 410A, 411, 412A, designated $M$ in Table 1). Two samples were investigated at the University of Minnesota ( $\mathrm{M}_{\mathrm{N}}$ in Table 1). The Tokyo instrument is a horizontal torsion balance which eliminates any effect of weight changes of sample on the automatically recorded magnetization changes. A chip of rock of about 100 to 150 milligrams was used for each measurement. A field of approximately 4300 Oe was applied throughout the heating and cooling cycles. The rate of heating and cooling was $6^{\circ} \mathrm{C} / \mathrm{min}$. The samples were kept at maximum temperature (usually $620^{\circ} \mathrm{C}$ ) for half an hour before cooling. All samples were heated in a vacuum of $10^{-4}$ Torr, using a diffusion pump without a liquid nitrogen trap.

The University of Wyoming instrument uses a Cahn microbalance. Small chips weighing about 180 milligrams were heated in a field of 4150 Oe at a rate of 25 to $30^{\circ} \mathrm{C} / \mathrm{min}$. Samples were taken to $700^{\circ} \mathrm{C}$ and cooled immediately at the same rate. A vacuum between $10^{-4}$ to $10^{-5}$ Torr was

\footnotetext{
${ }^{1}$ Ocean Research Institute, University of Tokyo.

${ }^{2}$ University of Wyoming, Laramie

${ }^{3}$ University of Leeds, Leeds, England.

${ }^{4}$ University of California, Santa Barbara.
}

maintained by a diffusion pump, also without a liquid nitrogen trap. In addition to the Tokyo and Wyoming determinations, two $J_{s}-T$ curves were obtained on a vibrating sample magnetometer at the University of Minnesota. The magnetic field used was $2500 \mathrm{Oe}$, and heating was done in a vacuum of less than $1 \times 10^{-6}$ Torr. The heating rate was about 10 to $15^{\circ} \mathrm{C} / \mathrm{min}$. The difference in heating and cooling procedures and in heating rates has caused slight differences between the $\mathrm{J}_{\mathrm{s}}-\mathrm{T}$ curves determined at Tokyo and those determined at Wyoming. In particular, more of the reversible type curves were obtained at Wyoming, and more frequently Tokyo curves had three intensity drops before a completely paramagnetic state is reached than did Wyoming curves.

As already seen in previous work (Ozima et al., 1968), two types of samples can be distinguished from their thermomagnetic behavior: a thermally reversible type (Figure 1a) and an irreversible one (Figure 1b). With irreversible samples, magnetization generally decreases with increasing temperature, to reach nearly zero or a minimum value at a certain temperature $\left(\mathrm{T}_{1}\right)$, and increases with further heating until it finally becomes paramagnetic above a higher Curie temperature. Several samples show two high-temperature peaks, as indicated in Figure 1c ( $\mathrm{Tc}_{2}$ and $\mathrm{Tc}_{3}$ in Table 1). These peaks can be explained as titanomaghemite undergoing a two-stage inversion to low-Ti spinel plus hemoilmenite.

The Curie temperatures of the high-temperature phases $\left(\mathrm{T}_{\mathrm{cH}}\right)$, which are determined from the cooling curves after heating to $620^{\circ}$ to $700^{\circ} \mathrm{C}$, are as listed in Table 1 . Some consistency is evident, either within an entire site, or in various levels at a site; this suggests a similar magnetic phase through some thickness of basalt. The ratio of magnetization at room temperature before heating $\left(\mathrm{J}_{\mathrm{o}}\right)$ to that obtained after the heating-cooling cycle $\left(\mathrm{J}_{\mathrm{Ho}}\right)$ is also listed. The ratio ranges from 0.75 to 7.53 , but most frequently falls between 1 and 3 (Table 1). There seems to be a general tendency for the ratio $\mathrm{J}_{\mathrm{Ho}} / \mathrm{J}_{\mathrm{o}}$ to increase with the Curie temperature of the high-temperature phase $\left(\mathrm{T}_{\mathrm{cH}}\right)$ (Figure 2). Decomposition of titanomaghemite to less titaniferous titanomagnetite plus hemoilmenite would cause $\mathrm{J}_{\mathrm{Ho}} / \mathrm{J}_{\mathrm{o}}$ values greater than unity.

There are several samples with unusual thermomagnetic features. One unusual curve is from a sample in a lower unit of Hole 409; it shows reversible thermomagnetism curves but a Curie temperature of roughly $540^{\circ}$ (Figure 3a). This suggests an unoxidized titanomagnetite close to magnetite, such as is commonly found in island-arc volcanic belts. The flow unit of this sample is petrographically different from the others, and is regarded as a product of highly differentiated magma (labeled as a tholeiitic andesite in the 
TABLE 1

Summary of Thermomagnetic Properties and Crystallographic and Chemical Characteristics of the Samples Treated in This Study

\begin{tabular}{|c|c|c|c|c|c|c|c|c|c|c|c|c|c|}
\hline \multirow{2}{*}{$\begin{array}{c}\text { Core- } \\
\text { Section }\end{array}$} & \multirow{2}{*}{$\begin{array}{l}\text { Depth } \\
(\mathrm{m})\end{array}$} & \multirow{2}{*}{$\begin{array}{l}\text { Thermomag. } \\
\text { Reversibility }\end{array}$} & \multicolumn{4}{|c|}{ Curie Temperature $\left({ }^{\circ} \mathrm{C}\right)$} & & & $\mathrm{Fe} / \mathrm{Ti}$ & & Size of Mag & Oxidation & \\
\hline & & & $\mathrm{Tc}_{1}$ & $\mathrm{Tc}_{2}$ & $\mathrm{Tc}_{3}$ & $\mathrm{Tc}_{\mathrm{H}}$ & ${ }^{\mathrm{J}} \mathrm{Ho} / \mathrm{Jo}$ & (A) & (Mole) & $\mathrm{x}$ Value & Mineral $(\mu \mathrm{m})$ & Stage ${ }^{a}$ & Observer \\
\hline Hole 407 & & & & & & & & & & & & & \\
\hline $33 \mathrm{CC}$ & 300.5 & (R) & 485 & - & - & 440 & 0.75 & n.d. & 27.7 & 0.65 & $10 \sim 20$ & & $\mathrm{~K}$ \\
\hline $35-1$ & 319.9 & I & 213 & 438 & - & 430 & 1.39 & n.d. & n.d. & n.d. & & & $\mathrm{K}$ \\
\hline $36-2$ & 330.3 & n.d. & n.d. & & & & n.d. & n.d. & 27.7 & 0.65 & $0.5 \sim 30$ & 2 & $\mathrm{~F}$ \\
\hline $36-2$ & 331.3 & (R) & 212 & 485 & - & 180 & 1.14 & 8.437 & 26.4 & 0.63 & $10 \sim 50$ & & $\mathrm{~K}$ \\
\hline $36-3$ & 332.2 & n.d. & n.d. & & & & n.d. & n.d. & 29.4 & 0.68 & n.d. & & $\mathrm{F}$ \\
\hline $37-1$ & 338.8 & n.d. & n.d. & & & & n.d. & n.d. & 30.4 & 0.70 & n.d. & & F \\
\hline $37-1$ & 339.3 & $\mathrm{R}$ & 145 & - & - & 125 & 1.12 & 8.442 & 29.4 & 0.68 & $\sim 100$ & & $\mathrm{~K}$ \\
\hline $37-2$ & 340.8 & $\mathrm{R}$ & 128 & - & - & 80 & 1.00 & n.d. & 31.7 & 0.72 & & & $\mathrm{~K}$ \\
\hline $38-1$ & 348.5 & I & 213 & 385 & 530 & 505 & 4.27 & n.d. & n.d. & n.d. & $0.5 \sim 5$ & 3 & $\mathrm{~K}$ \\
\hline $38-1$ & 348.6 & I & 240 & 435 & 540 & 565 & 2.30 & n.d. & n.d. & n.d. & n.d. & & M \\
\hline $38-2$ & 349.9 & I & 235 & 380 & 535 & 490 & 3.17 & n.d. & n.d. & n.d. & n.d. & & $\mathrm{K}$ \\
\hline $38-3$ & 352.4 & n.d. & n.d. & & & & & n.d. & 27.8 & 0.63 & n.d. & & $\mathrm{F}$ \\
\hline $38-3$ & 351.7 & 1 & 222 & $(390)$ & 485 & 440 & 2.13 & 8.405 & 34.1 & 0.76 & $10 \sim 100$ & & K \\
\hline $38-3$ & 351.8 & i & 200 & 453 & - & 415 & 1.43 & n.d. & 34.7 & 0.77 & $<10$ & & $\mathrm{~K}$ \\
\hline $39-2$ & 359.6 & $\mathrm{i}$ & 220 & 420 & - & 430 & 1.31 & n.d. & n.d. & n.d. & n.d. & & $\mathrm{K}$ \\
\hline $39-3$ & 360.7 & (R) & 170 & - & - & 345 & 1.18 & n.d. & n.d. & n.d. & n.d. & & M \\
\hline $39-3$ & 360.9 & 1 & 200 & 462 & - & 420 & 1.18 & n.d. & n.d. & n.d. & n.d. & & K \\
\hline $39-3$ & 361.0 & $\mathrm{R}$ & 140 & - & - & 110 & 1.00 & n.d. & 28.3 & 0.66 & n.d. & 3 & $\mathrm{~K}$ \\
\hline $39-3$ & 361.9 & n.d. & n.d. & & & & & n.d. & 25.5 & 0.61 & $<5$ & & $\mathrm{~F}$ \\
\hline $40-1$ & 367.6 & 1 & 222 & 370 & 540 & 490 & 4.40 & 8.402 & 33.3 & 0.74 & $5 \sim 10$ & & $\mathrm{~K}$ \\
\hline $42-1$ & 386.9 & I & 190 & 457 & - & 430 & 1.72 & n.d. & n.d. & n.d. & n.d. & & $\mathrm{K}$ \\
\hline $42-2$ & 388.8 & $\mathrm{R}$ & 140 & - & - & 330 & 1.20 & n.d. & n.d. & n.d. & n.d. & & $\mathrm{K}$ \\
\hline $44-1$ & 424.2 & I & 295 & 508 & - & 500 & 1.96 & n.d. & 31.8 & 0.72 & $<5$ & & $\mathrm{~K}$ \\
\hline $45-1$ & 434.2 & I & 223 & 460 & - & 435 & 0.76 & n.d. & n.d. & n.d. & n.d. & 3 & $\mathrm{~K}$ \\
\hline $45-2$ & 435.4 & I & 345 & 553 & - & 525 & 4.55 & n.d. & 30.4 & 0.70 & n.d. & & $\mathrm{K}$ \\
\hline $45-2$ & 436.4 & I & 270 & 565 & - & 570 & 5.66 & n.d. & n.d. & n.d. & n.d. & & M \\
\hline $45-3$ & 437.7 & 1 & 220 & 462 & - & 430 & 1.53 & n.d. & 29.4 & 0.68 & n.d. & & K \\
\hline $45-4$ & 438.5 & (R) & 250 & 452 & - & 410 & 1.02 & n.d. & 28.3 & 0.66 & n.d. & & K \\
\hline $46-1$ & 443.1 & n.d. & n.d. & & & & & n.d. & 28.3 & 0.66 & n.d. & & $\mathrm{F}$ \\
\hline $46-3$ & 446.7 & 1 & 340 & 575 & - & 550 & 5.01 & n.d. & n.d. & n.d. & n.d. & $3 \sim 4$ & M \\
\hline $46-3$ & 447.3 & I & 400 & 605 & - & 525 & 2.15 & n.d. & n.d. & n.d. & n.d. & & $\mathrm{K}$ \\
\hline $46-4$ & 448.2 & I & 340 & 560 & - & 525 & 5.90 & n.d. & n.d. & n.d. & n.d. & & $\mathrm{K}$ \\
\hline $47-1$ & 453.7 & I & 315 & 560 & - & 580 & 6.96 & n.d. & n.d. & n.d. & n.d. & & M \\
\hline $47-2$ & 454.2 & I & 220 & 550 & - & 520 & 4.15 & n.d. & n.d. & n.d. & n.d. & & K \\
\hline $47-2$ & 454.9 & I & 273 & 477 & 562 & 530 & 4.81 & n.d. & n.d. & n.d. & n.d. & & $\mathrm{K}$ \\
\hline $47-3$ & 455.7 & I & 235 & 465 & - & 450 & 1.71 & n.d. & n.d. & n.d. & n.d. & & K \\
\hline $47-3$ & 456.2 & $\mathrm{R}$ & 195 & - & - & 190 & 0.92 & n.d. & n.d. & n.d. & n.d. & & M \\
\hline $47-4$ & 457.4 & I & 310 & 555 & - & 520 & 4.85 & n.d. & 30.4 & 0.70 & $<10$ & & K \\
\hline Hole 408 & & & & & & & & & & & & & \\
\hline $35-1$ & 323.8 & n.d. & n.d. & & & & & n.d. & 40.2 & 0.86 & $10 \sim 100$ & & $\mathrm{~F}$ \\
\hline $35-1$ & 324.1 & I & 360 & 500 & 555 & 525 & 3.73 & n.d. & 22.0 & 0.54 & 5 & & $\mathrm{~K}$ \\
\hline $36-2$ & 335.4 & 1 & 295 & 545 & - & 545 & 3.89 & n.d. & n.d. & n.d. & n.d. & & M \\
\hline $36-5$ & 339.0 & 1 & 335 & 530 & - & 530 & n.d. & n.d. & n.d. & n.d. & n.d. & $3 \sim 4$ & $\mathrm{M}_{\mathrm{N}}$ \\
\hline $37-1$ & 342.1 & n.d. & n.d. & & & & & n.d. & 28.3 & 0.66 & n.d. & & $\mathrm{F}$ \\
\hline $37-1$ & 343.0 & $\mathrm{R}$ & 210 & - & - & 250 & 0.94 & n.d. & n.d. & n.d. & n.d. & & M \\
\hline $37-1$ & 343.2 & n.d. & n.d. & & & & & n.d. & 22.4 & 0.55 & n.d. & & $\mathrm{F}$ \\
\hline $37-3$ & 346.1 & $\mathrm{R}$ & 185 & - & - & 260 & 1.13 & n.d. & 26.1 & 0.62 & $10 \sim 100$ & & K \\
\hline $38-1$ & 352.2 & n.d. & n.d. & & & & & n.d. & 26.6 & 0.63 & n.d. & & $\mathrm{F}$ \\
\hline $38-2$ & 352.6 & (R) & 260 & 445 & - & 375 & 0.85 & n.d. & n.d. & n.d. & n.d. & & M \\
\hline Hole 409 & & & & & & & & & & & & & \\
\hline $7-6 \mathrm{~B}$ & 80.0 & (R) & 160 & - & - & 260 & 1.10 & n.d. & 27.4 & 0.64 & $5 \sim 10$ & & $\mathrm{~K}$ \\
\hline 7.7 & 81.1 & $\mathrm{R}$ & 200 & - & - & 200 & 1.10 & n.d. & n.d. & n.d. & n.d. & 2 & $\mathrm{M}$ \\
\hline $9-1$ & 91.1 & 1 & 278 & 483 & - & 460 & 1.47 & n.d. & n.d. & n.d. & n.d. & & $\mathrm{K}$ \\
\hline $9-3$ & 94.2 & I & 310 & (490) & 547 & 515 & 2.50 & n.d. & 33.3 & 0.75 & $5 \sim 10$ & & $\mathrm{~K}$ \\
\hline $10-1$ & 100.6 & $\mathrm{R}$ & 143 & - & - & 120 & 1.00 & n.d. & 28.5 & 0.66 & $>10$ & & $\mathrm{~K}$ \\
\hline $10-2$ & 102.3 & 1 & 200 & 513 & - & 480 & 3.30 & n.d. & 35.3 & 0.78 & $>10$ & & K \\
\hline $10-6$ & 109.4 & $\mathrm{R}$ & 210 & - & - & 215 & 0.89 & n.d. & n.d. & n.d. & n.d. & & M \\
\hline $11-3$ & 113.8 & $\mathrm{R}$ & 143 & - & - & 120 & 1.00 & n.d. & 26.5 & 0.63 & $>10$ & & $\mathrm{~K}$ \\
\hline $11-4$ & 114.9 & n.d. & n.d. & & & & & n.d. & n.d. & 0.70 & n.d. & & $\mathrm{F}$ \\
\hline $12-1$ & 120.9 & 1 & 245 & 465 & - & 560 & 3.08 & n.d. & n.d. & n.d. & n.d. & 3 & M \\
\hline $15-1$ & 148.3 & n.d. & n.d. & & & & & n.d. & 26.1 & 0.62 & n.d. & & $\mathrm{F}$ \\
\hline $15-2$ & 149.9 & 1 & 255 & 475 & - & 540 & 2.44 & n.d. & n.d. & n.d. & n.d. & 3 & M \\
\hline $15-4$ & 153.1 & I & 218 & 480 & 550 & 540 & 7.53 & n.d. & 36.4 & 0.80 & $>10$ & & $\mathrm{~K}$ \\
\hline $15-5$ & 154.7 & I & 245 & 495 & 550 & 570 & 6.19 & n.d. & n.d. & n.d. & n.d. & $3 \sim 4$ & M \\
\hline $15-6$ & 156.8 & I & 235 & 495 & - & 505 & 2.21 & n.d. & n.d. & n.d. & n.d. & & M \\
\hline $16-1$ & 158.7 & I & 222 & 480 & 550 & 540 & 5.66 & n.d. & 35.5 & 0.78 & n.d. & & $\mathrm{K}$ \\
\hline $16-2$ & 159.2 & I & 335 & 500 & - & 470 & 1.81 & n.d. & n.d. & n.d. & n.d. & & $\mathrm{K}$ \\
\hline $17-1$ & 167.4 & n.d. & n.d. & & & & & n.d. & n.d. & 0.62 & n.d. & & $\mathrm{F}$ \\
\hline $18-2$ & 179.0 & 1 & 222 & 480 & 550 & 540 & 6.48 & n.d. & n.d. & n.d. & n.d. & & K \\
\hline $21-1$ & 206.0 & I & 230 & 450 & - & 495 & 2.51 & n.d. & n.d. & n.d. & n.d. & & M \\
\hline $22-1$ & 217.1 & I & 208 & 485 & - & 430 & 2.26 & n.d. & 30.9 & 0.71 & n.d. & & $\mathrm{K}$ \\
\hline $23-1$ & 224.3 & I & 220 & 500 & - & 460 & 2.73 & n.d. & n.d. & n.d. & n.d. & & M \\
\hline $24-1$ & 233.7 & (R) & 295 & 480 & - & 340 & 0.92 & n.d. & 28.3 & 0.67 & $>10$ & & $\mathrm{~K}$ \\
\hline
\end{tabular}


TABLE 1 - Continued

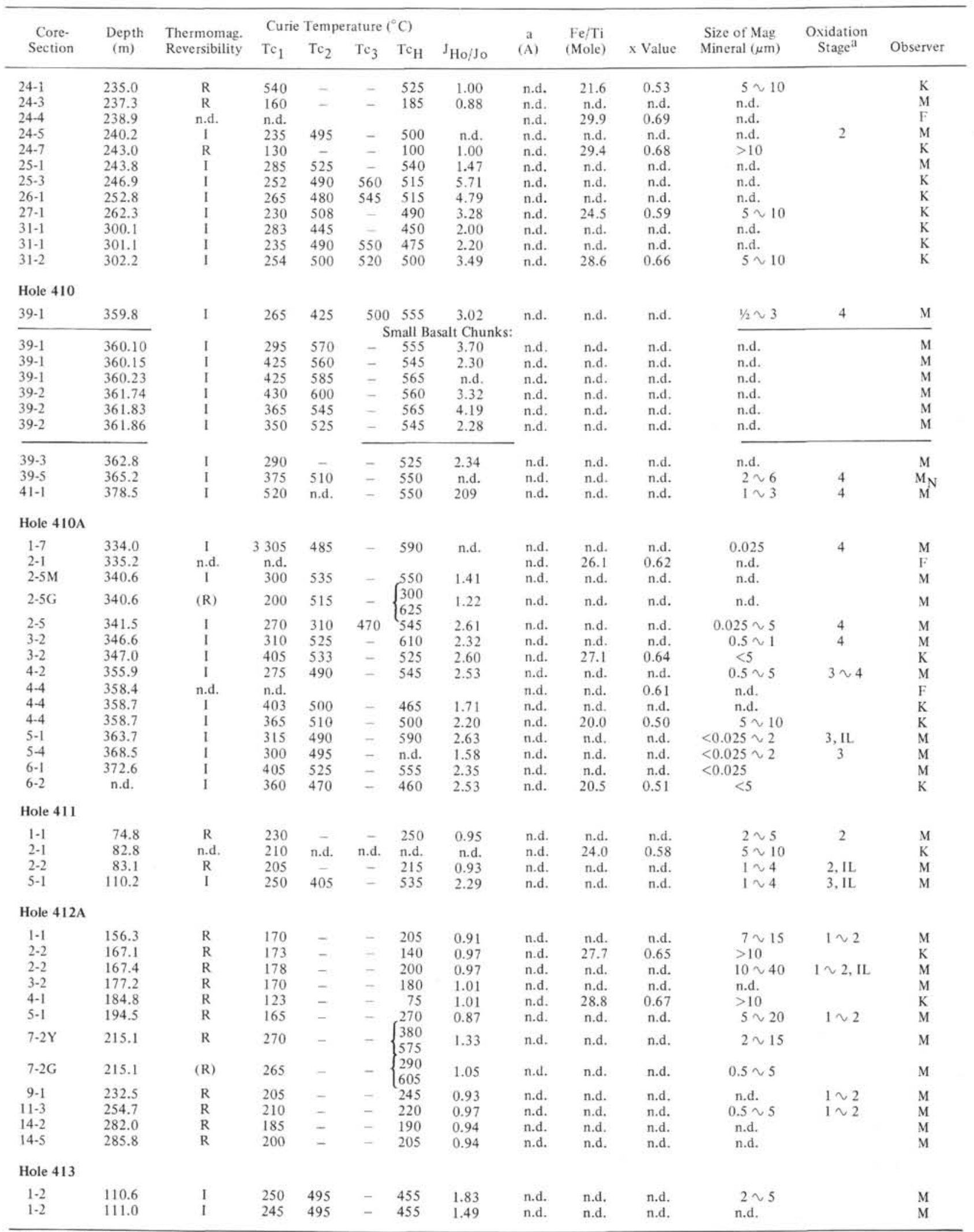

a After Johnson and Hall (1978).

Note: Observers: $\mathrm{K}$, at Tokyo; $\mathrm{M}$, at Wyoming; $\mathrm{F}$, at Leeds; and $\mathrm{MN}_{\mathrm{N}}$, at Minnesota. n.d. $=$ no data, $\mathrm{R}=$ reversible, $\mathrm{I}=\mathrm{irreversible,}(\mathrm{R})=\mathrm{partially}$ reversible, as discussed in the text. The sizes quoted are rough values of the most aboundant grain size. 


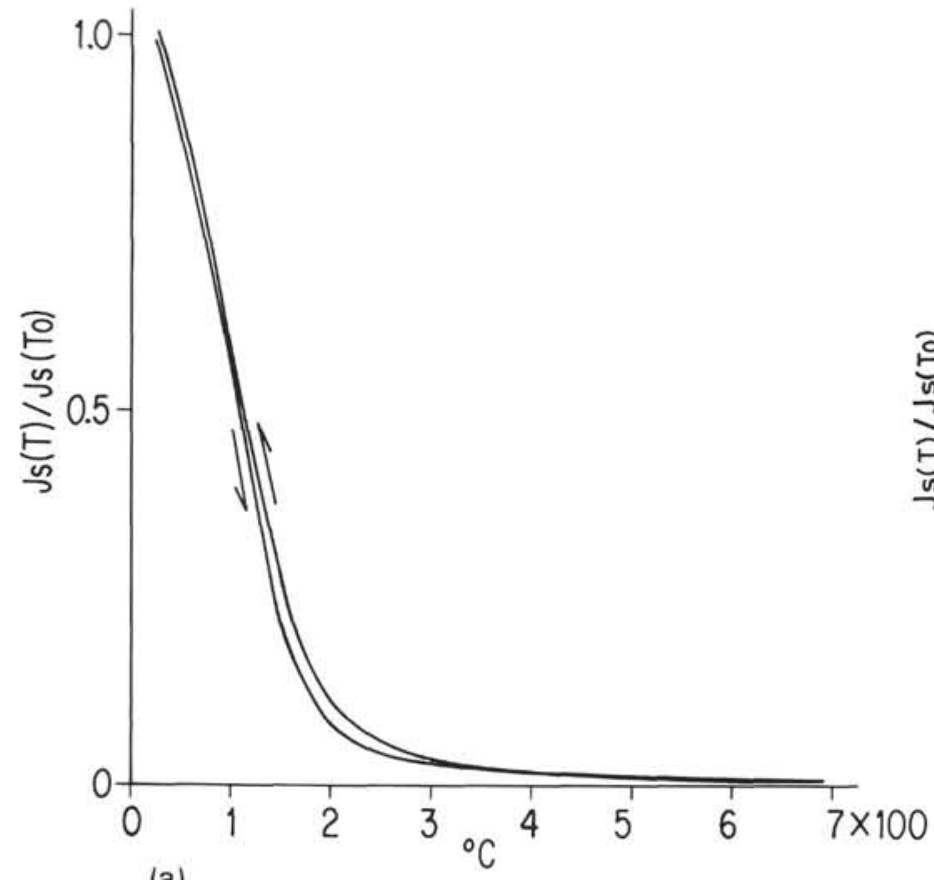

(a)

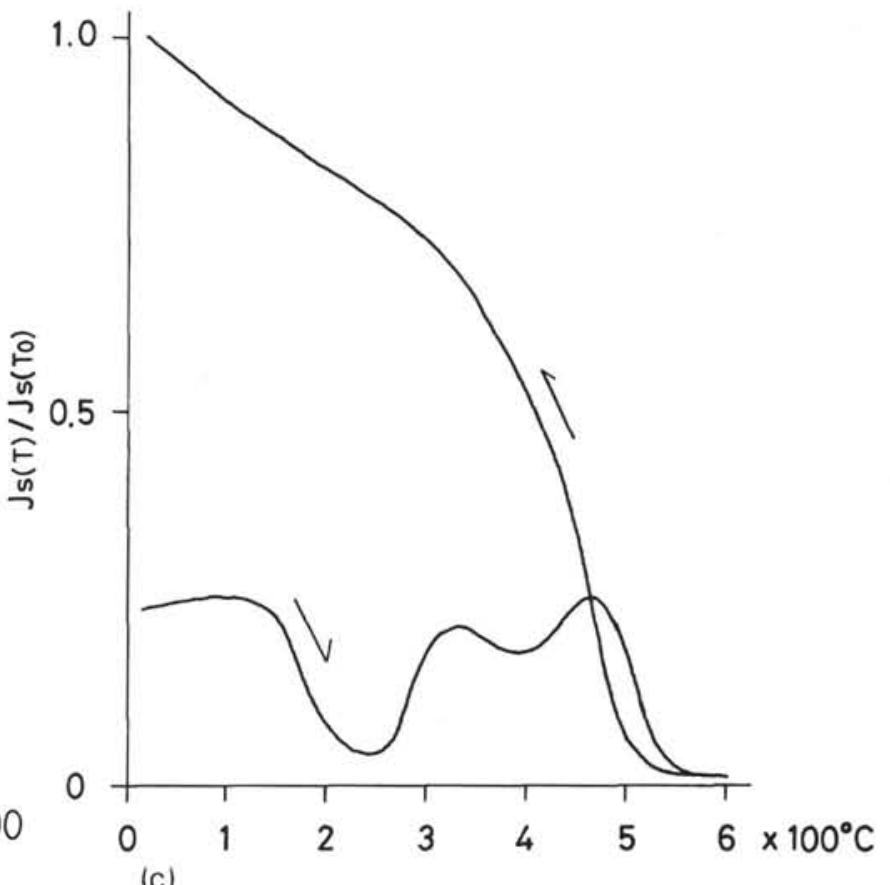

(c)

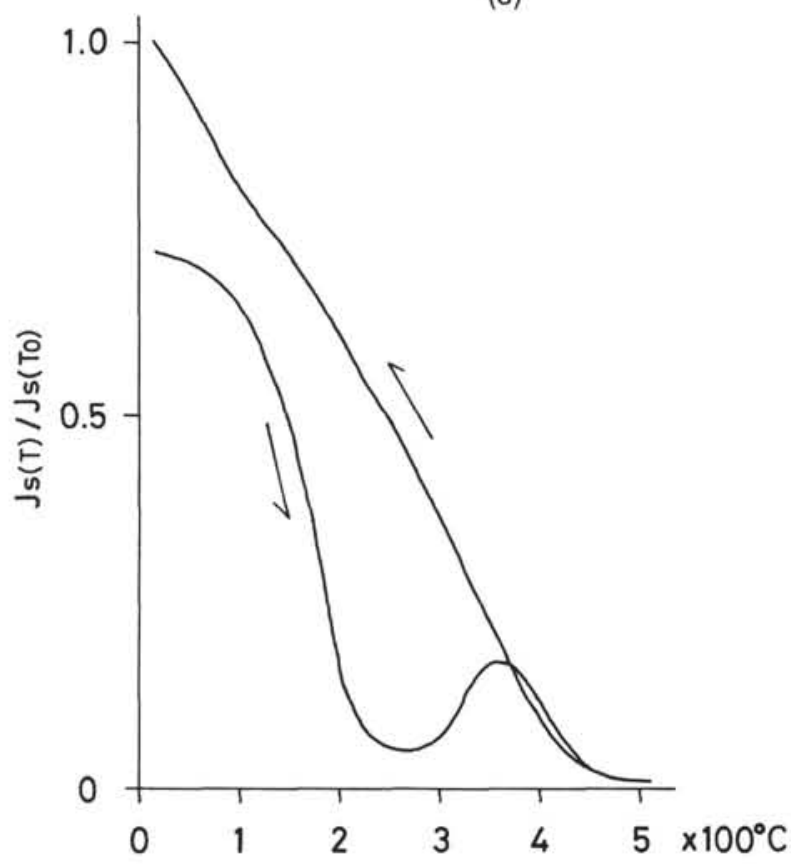

(b)

Figure 1. Thermomagnetism curves of typical samples. (a) thermally reversible type, 412A-3-2. (b) thermally irreversible type with one peak in $J_{S}-T, 407-35-1$. (c) thermally irreversible type with two peaks in $J_{S}-T, 407-38-1$.

shipboard nomenclature). It is likely that this distinct petrologic circumstance produced opaque minerals formed under conditions much different from those in the typical oceanic basalts. This sample is also unusual in other magnetic properties (see Day et al., this volume).

Another sample, the first piece of basalt recovered at Hole 407 (33, CC of Table 1), also shows a reversible high Curie temperature. This rock was collected by the core catcher at the sub-basement surface, and may be a fragment of rock transported from an adjacent area. It will be excluded in the following discussion.
An occasional sample shows a secondary $\mathrm{J}_{\mathrm{s}}-\mathrm{T}$ peak in the heating, but the $\mathrm{J}_{\mathrm{s}}-\mathrm{T}$ curve in the cooling process is more similar to the heating portion of the $\mathrm{J}_{\mathrm{s}}$ - $\mathrm{T}$ curve at the lower temperatures before the peak appears (Figure 1e). This type of sample (Figure $3 \mathrm{~b}$ ) is classified as partially reversible (R) in Table 1. Except for the one above-mentioned tholeiitic andesite sample, the Curie temperatures of the reversible samples are lower than the initial Curie temperatures $\left(\mathrm{T}_{\mathrm{c}}\right)$ of the irreversible types.

Several characteristic features can be recognized in the thermomagnetic properties of each hole. In Hole 407, the 


\section{$\mathrm{J}_{\mathrm{H}} / \mathrm{J}_{\mathrm{O}}$}
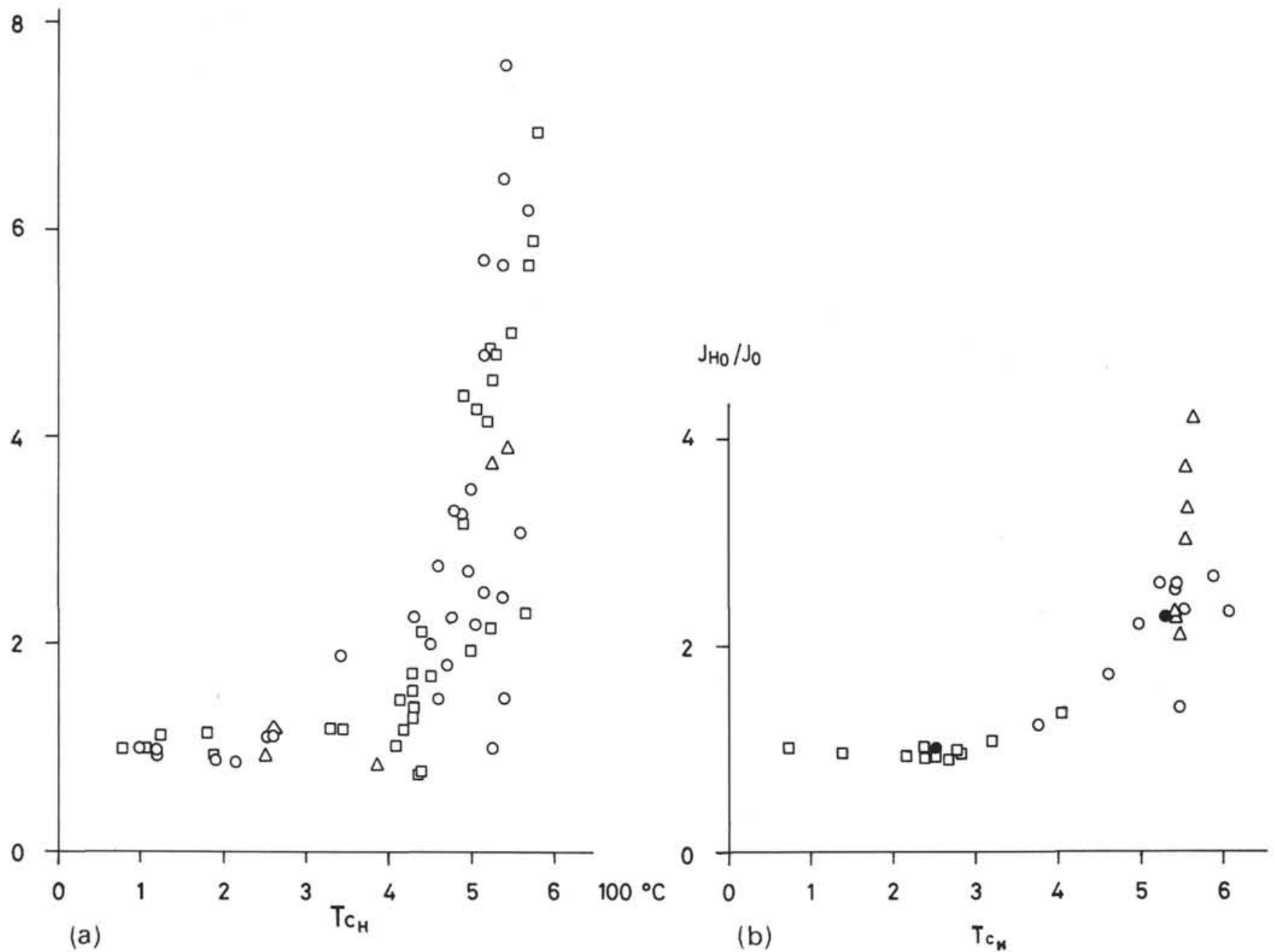

Figure 2. $J_{H_{O}} / J_{O}$ versus $T_{c H}$ diagrams, showing their correlation. (a) $\square$ Hole $407, \Delta$ Hole 408 , $\circ$ Hole 409 . (b) $<$ Hole oHole 410A, $\bullet$ Hole 411, 口 Hole 412A.

initial Curie temperature $\left(\mathrm{T}_{\mathrm{cl}}\right)$ in the lower part is about $100^{\circ} \mathrm{C}$ higher than in the upper part (Figure 4a). Reversible samples occur in a few units at different depths in the upper part of the hole, in both the normal and reversed magnetic units. Irreversible samples are frequently situated within 1 to 2 meters of reversible ones. In the lower paleomagnetic unit of the hole, however, below the gap in recovery, almost all samples are irreversible (Figure 4a). This difference coincides with a change in inclinations at that point.

The upper half of Hole 408 (above the sub-bottom depth $344 \mathrm{~m}$ ) is wholly irreversible; the lower half is reversible (Table 1). The boundary coincides with a boundary in the paleomagnetism results, in other rock magnetic studies (Day et al., this volume), in petrographic examination of the opaque minerals (discussed later), as well as in alteration of the whole rocks, obvious to the unaided eye.

Despite the excellent recovery of samples representing 200 meters of basalt, no systematic variations in thermomagnetic properties with depth are evident in Hole 409 (Figure 4b). The reversible high- $\mathrm{T}_{\mathrm{c}}$ tholeiitic andesite occurs at about 150 meters. Values of the initial Curie temperatures and frequency of occurrence of thermally reversible samples from this hole (about $2 \mathrm{~m}$.y. age) are not significantly different from Hole 407 (about 40 m.y.). This indicates that, in the North Atlantic, the thermomagnetic properties of the ocean floor basalts may be independent of age between $2 \mathrm{~m} . \mathrm{y}$. and $40 \mathrm{~m} . \mathrm{y}$, in contrast to the previous postulations of age-dependence of magnetic features attributable to gradual oxidation (Carmichael, 1970; Irving et al., 1970).

Hole 410, a basalt limestone breccia, shows the highest values of the initial Curie temperature (around $380^{\circ} \mathrm{C}$ ) of any Leg 49 hole (Table 1). All samples from this hole have irreversible thermomagnetism curves. The data shown in Table 1 pertain to samples from large chunks of basalt within the breccia and to samples from much smaller basalt pieces within the breccia (see Site Summary Chapter, Site 410 , this volume). Curie temperatures are notably more uniform among the small breccia pieces than among the larger ones. This probably reflects a hot origin of the breccia 


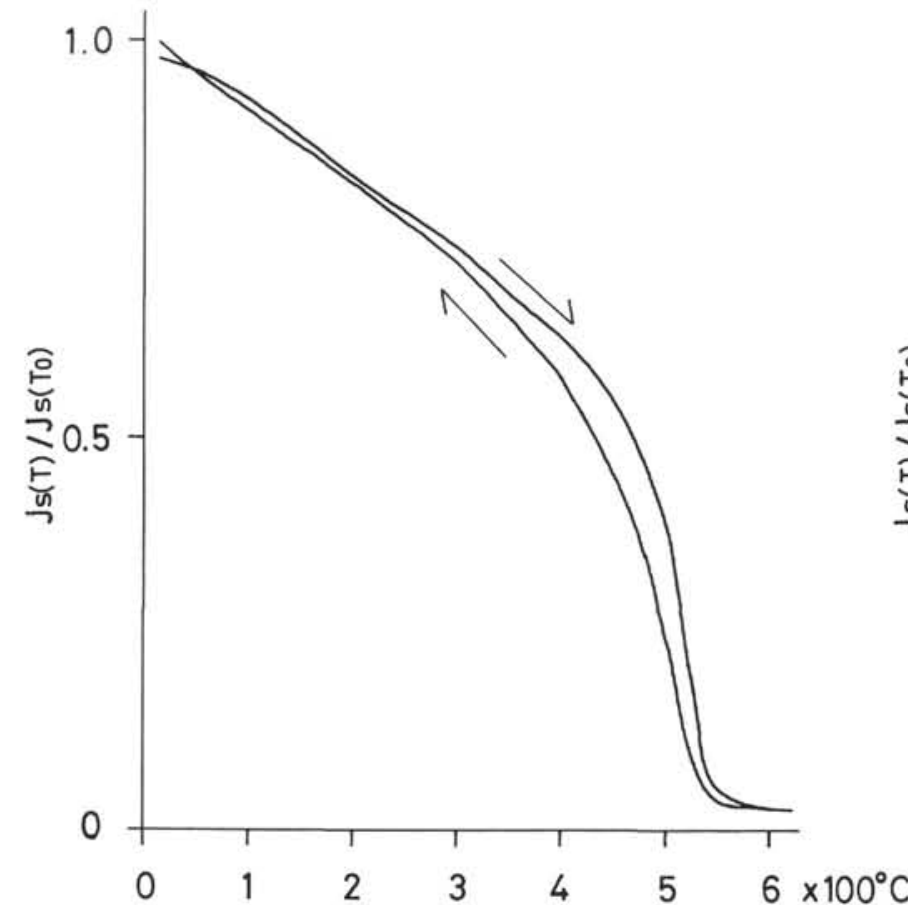

(a)

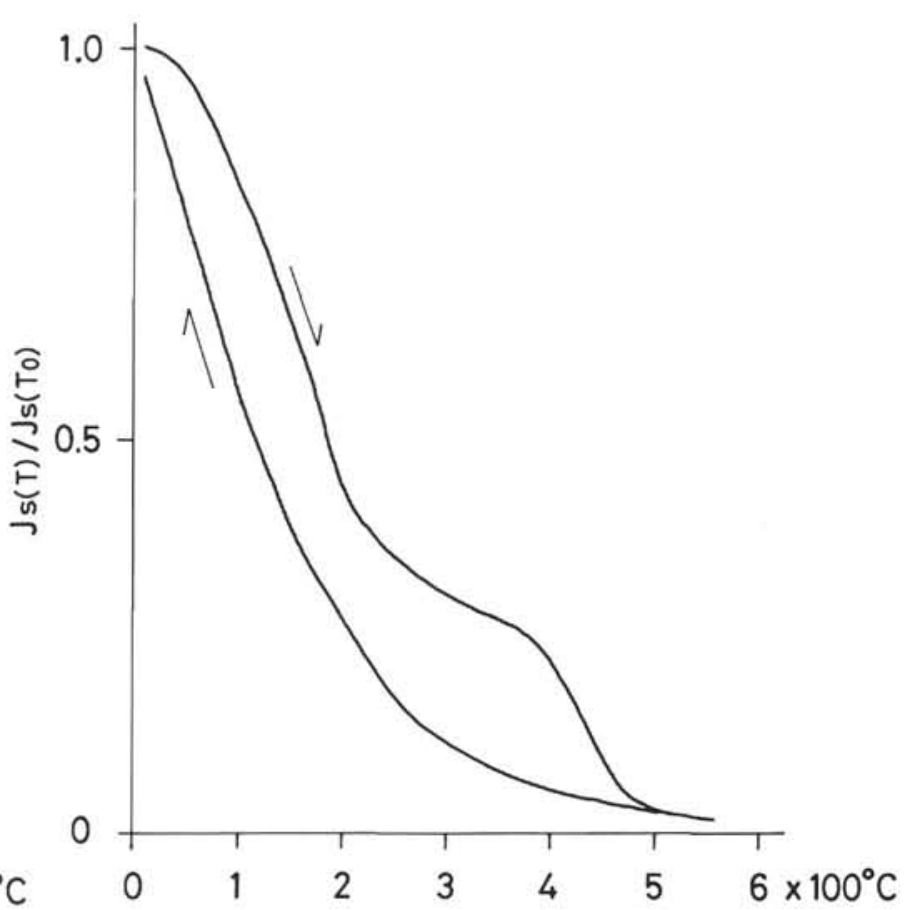

(b)

Figure 3. (a) thermally reversible with a high Curie temperature, 409-24-1 (tholeïtic andesite). (b) partially reversible type (see test) 409-24-1. The difference between the heating and cooling curves at low temperatures may reflect a thermal lag problem.

and the higher temperatures attained by the smaller pieces compared with the larger ones. The Curie temperatures of the high-temperature phases of all samples are concentrated around $540^{\circ} \mathrm{C}$. The ratio $\mathrm{J}_{\mathrm{Ho}} / \mathrm{J}_{\mathrm{O}}$ is distributed around 3.0 . In no sample from Hole 410 does this ratio exceed 5.0 - in contrast to Holes 407 and 409 , in which a notable fraction of irreversible samples have a ratio of 4.5 to 7.0 (Figures $4 d$, $3 \mathrm{a}$, and $3 \mathrm{~b}$ ). This implies that the titanomagnetite in Hole 410 has been extensively oxidized. It seems likely that oxidation proceeded when the rock was brecciated and reacted with seawater at a high temperature.

The initial Curie temperatures of samples from Hole $410 \mathrm{~A}$ are very uniform with depth, and their average is lower than that of Hole 410 by about $100^{\circ} \mathrm{C}$. Nevertheless, all (except a glassy margin of a flow) display irreversible thermomagnetism curves. A comparison measurement was made between a glass and the margin of the glass. As might be expected, the glass has a lower Curie temperature than the immediate margin rock (Figures $5 \mathrm{c}$ and $5 \mathrm{~d}$ ) and is more reversible, indicating that it has been less oxidized. The values of $\mathrm{T}_{\mathrm{cH}}$ in the Hole 410A are more scattered, and their average is slightly lower than for Hole 410 . The difference between the two sites may be a result of different degrees of oxidation (Hole $410 \mathrm{~A}$ is less oxidized), although titanomagnetites in both holes appear to be oxidized to a large extent as far as the thermomagnetic behavior (and microscopic properties, discussed later) is concerned (Figure 4c).

Hole 411 , which has the most recently formed basement ( 1.0 m.y.) among holes of Leg 49 (and even the youngest among holes so far drilled by DSDP), has reversible samples in the upper 10 meters and an irreversible sample below. Although only 35 meters were cored here, this difference in thermomagnetic characteristics (Table 1) is consistent with the paleomagnetic boundary defined by inclination and median destructive field (see Site Summary). The initial Curie temperatures are relatively high compared with those of other reversible samples.

Samples from Hole 412A (1.6 m.y.) are all reversible, and have low initial Curie temperatures. The values of the Curie temperatures are uniform throughout the hole and lower than those of the younger Hole 411 (Figure 4d). Two samples were measured from one paleomagnetic core which cuts an oxidation front so that one half is yellowish tan and the other gray. Curie temperatures are the same; the gray phase shows a nearly reversible curve (Figure 5a). The yellow portion shows two Curie temperatures, and is more irreversible (Figure 5b), but still not as irreversible as most irreversible samples from this leg (as illustrated in Figures $1 \mathrm{~b}$ and $1 \mathrm{c})$. It is interesting that this alteration is not as severe as it appears from the yellow color of the rocks. Although it drastically changes the rock color, the degree of oxidation is not as high as many of the irreversible samples in other holes.

It is, nevertheless, the most oxidized sample from Hole $412 \mathrm{~A}$, and the only sample displaying irreversibility. It would seem that the rocks at Hole $412 \mathrm{~A}$ have been under less oxidizing conditions than those of the other holes of similar age; both Site 411 (1 m.y.) and Site 409 (2 m.y.) are more oxidized than is Hole 412A. Normally, oxidation of titanomagnetite proceeds very rapidly after basalt formation (see discussion in Steiner et al., this volume). The low 

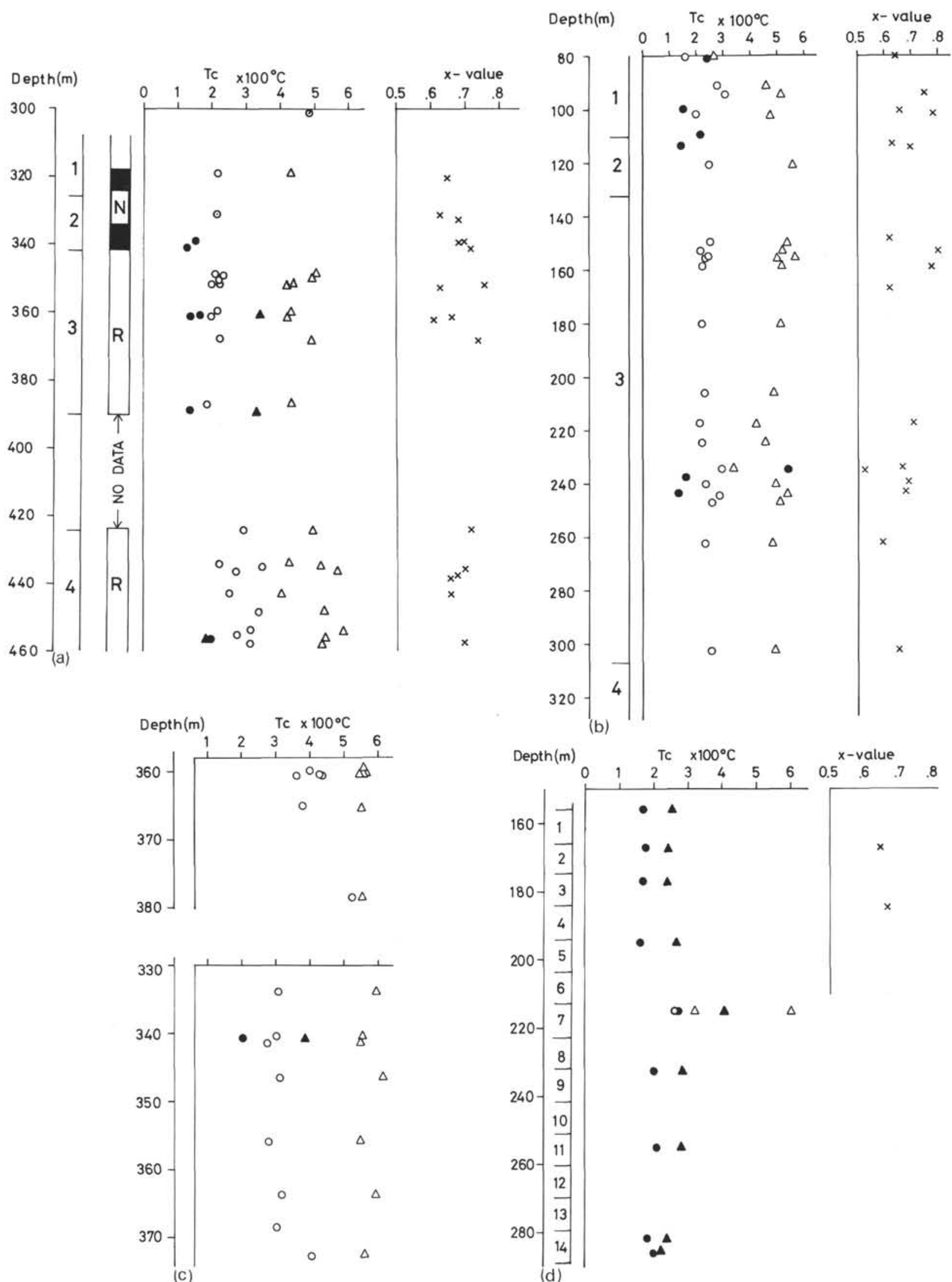

(b)

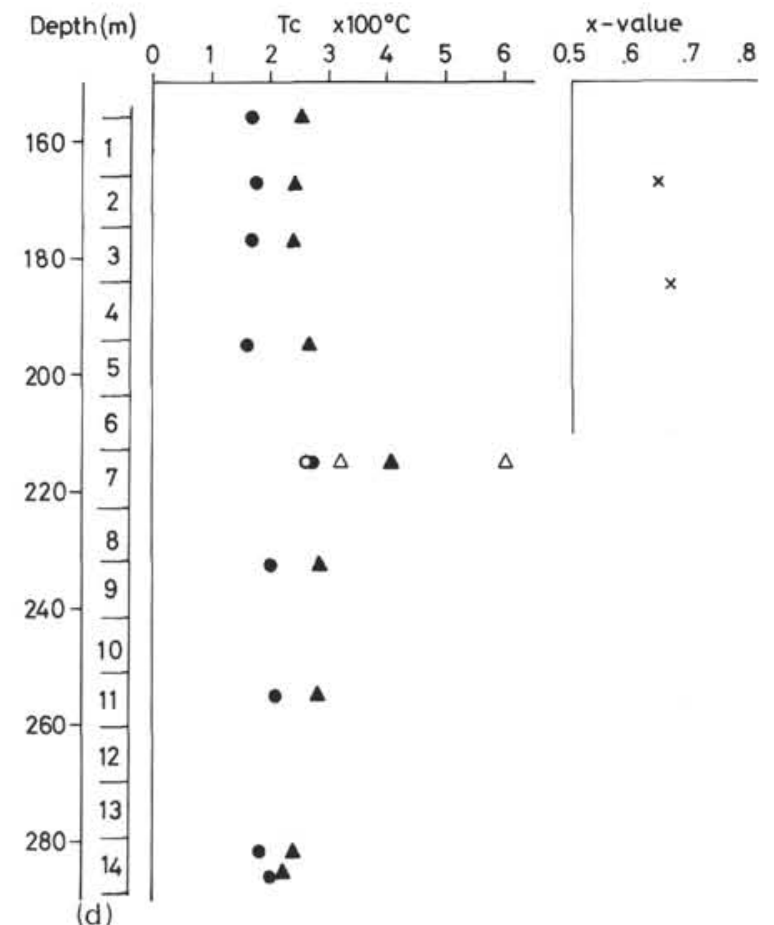

Figure 4. Downhole plots of $T_{c}\left(T_{c_{1}}\right.$ indicated by circles and $T_{C_{H}}$ by triangles, where solid marks denote reversible samples and hollow denote irreversible) and $x$ value (ulvospinel mole fraction in $x \mathrm{Fe}_{2} \mathrm{TiO}_{4} \cdot(1-x) \mathrm{Fe}_{3} \mathrm{O}_{4}$ solid solution). (a) Hole 407. (b) Hole 409. (c) Holes 410 (above) and 410A (below). ( $x$ value plots are not shown because of shortage of data). (d) Hole $412 \mathrm{~A}$. 


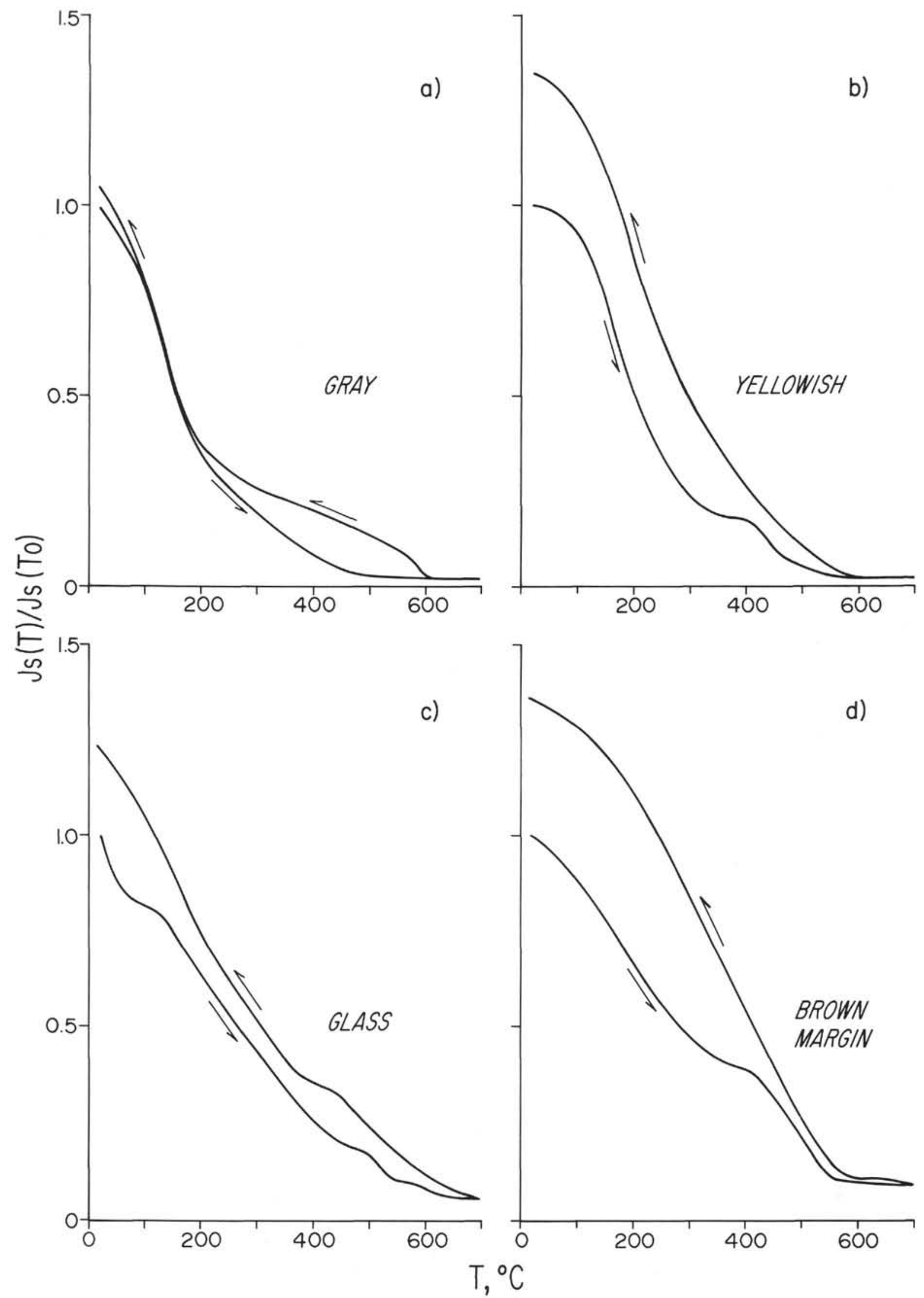

Figure 5. Comparison of Curie temperature curves of gray (a) versus yellow-brown (b) basalt across a color change (oxidation front) within one paleomagnetic sample $(2.5 \mathrm{~cm}$ diameter). Comparison of Curie temperature curves in glass (c) and in the immediate margin rock (d). 
Curie temperatures and the reversibility of Hole 412A samples suggest that the oxidation-reduction environment immediately or shortly after formation of the basement rocks must have been different, perhaps because of its location within a fracture zone.

\section{CHEMICAL COMPOSITION OF TITANOMAGNETITES CONTAINED IN THE ROCKS}

Fragments of rocks were polished and examined under a reflecting light microscope. Several particles of titanomagnetite or titanomaghemite were selected and analyzed by electron microprobes. Two instruments were used; one at the University of Tokyo (designated $\mathrm{K}$ in the last column of Table 1), and the other at University of Leeds (marked F). The atomic ratio $\mathrm{Ti} / \mathrm{Fe}$ was obtained, and the molecular fraction of ulvospinel $(x)$ in the ulvospinel-magnetite solid solution $\mathrm{CxFe}_{2} \mathrm{TiO}_{4} \cdot(1-\mathrm{x})$ $\left.\mathrm{Fe}_{3} \mathrm{O}_{4}\right]$ or its oxidized product was calculated on the assumption that the mineral is exclusively composed of $\mathrm{Fe}$, $\mathrm{Ti}$, and $\mathrm{O}$. Detailed analysis of a few samples indicated that content of metals other than $\mathrm{Fe}$ and $\mathrm{Ti}(\mathrm{Al}, \mathrm{Mn}$, etc.) is less than 1 wt per cent, which is negligibly small in the following consideration.

A significant correlation exists between the ulvospinel content ( $\mathrm{x}$ value) and the initial Curie temperature, $\mathrm{T}_{\mathrm{cl}}$; samples with higher $T_{\mathrm{c} 1}$ generally have a larger $\mathrm{x}$ value. This tendency is opposite to that with the stoichiometric (unoxidized) titanomagnetite series, in which the Curie temperature increases as the ulvospinel content ( $\mathrm{x}$ value) decreases. The present data suggest that samples with higher ulvospinel content are much more oxidized than those with lower ulvospinel content, since oxidation increases the Curie temperature as well. This is more clearly recognized when the results are plotted in the ternary compositional diagram $\left(\mathrm{TiO}_{2}-\mathrm{FeO}-\mathrm{Fe}_{2} \mathrm{O}_{3}\right)$ with contours of the Curie temperature (Figure 6). Diagrams are plotted for the three holes with the most samples. The solid and hollow circles in the figure distinguish reversible and irreversible thermomagnetic behavior. Distinct groups of the reversible and irreversible samples are obvious in the ternary diagrams.

Contours of the Curie temperature shown in this figure are after Ozima and Sakamoto (1971), whose data are somewhat different from those given by Readman and O'Reilly (1972). Recent experimental study shows that both contours need some revision. The general tendency considered here is, however, clearly demonstrated in either of the postulated diagrams. The circles in Figure 4 should therefore be understood as a demonstration of the semiquantitative correlation between $\mathrm{Ti}$ (or ulvospinel) content and the Curie temperature, and not as the precise representation of degree of oxidation.

The observed result, that the Ti content is higher in the more oxidized samples, may be explained by either of two processes: (1) The $\mathrm{Ti}$ content in the titanomagnetite was originally variable when the rock was solidified, and the high-Ti titanomagnetite was more easily oxidized than the low- $\mathrm{Ti}$ titanomagnetite in a similar environment. This explanation assumes that spinel-cubic crystals of
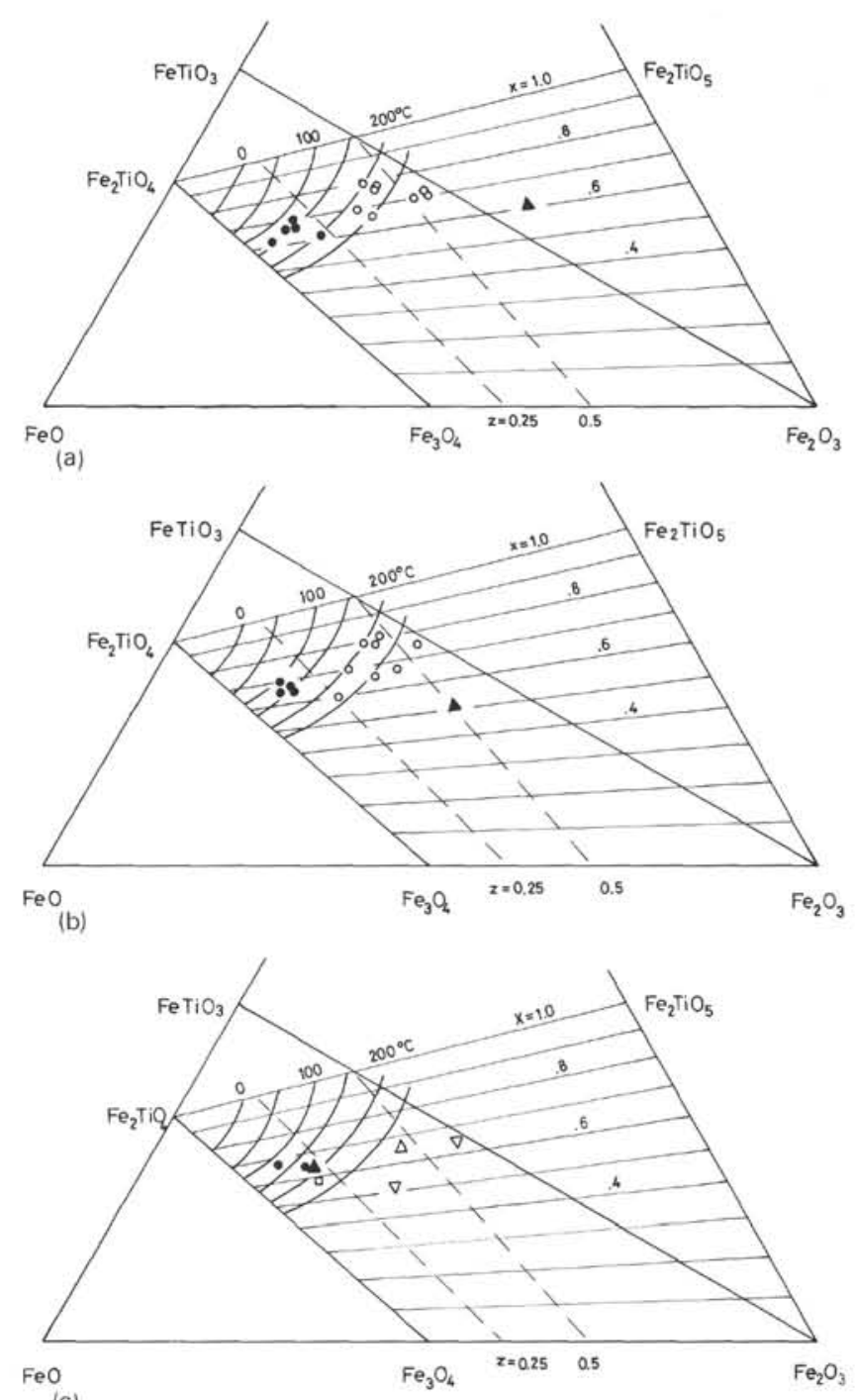

(c)

Figure 6. Ternary diagram showing distribution of $x$ values and the Curie temperatures. (See text for details.) Solid (hollow) circles indicate thermally reversible (irreversible) samples.

titanomagnetite are a closed system relative to $\mathrm{Fe}$ and $\mathrm{Ti}$, and that only $\mathrm{O}$ atoms can get in and out of the system. (2) The Ti content in the titanomagnetite was originally uniform in most of the basaltic units, with an x value of about 0.6 (the minimum asymptotic value in the least oxidized sample), and later, $\mathrm{Fe}^{3+}$ ions left the system to form the reddish staining in silicates (as fine hematite or goethite) as the low-temperature oxidation proceeded (Johnson and Hall, in press), causing gradual increase in Ti content of the oxidized titanomagnetite (titanomaghemite). In this case, the spinel-cubic phase is an open system relative to $\mathrm{Fe}^{3+}$.

Microscopic observation described in the following section indicates that the second explanation is more likely, since highly oxidized titanomagnetite is usually accompanied by reddish brown staining composed of iron hydroxides. The titanomaghemites observed to have $x$ values greater than 0.70 may be the result of oxidation of $x$ $=0.60$ titanomagnetites in which iron is removed from the 
lattice to form the red stain (Johnson and Hall, in press), thereby increasing the $\mathrm{Ti}$ content relative to $\mathrm{Fe}$. If so, the oceanic ridge basalts must have had a natural remanent magnetization originally of thermal origin, because the Curie temperature of unoxidized stoichiometric titanomagnetite with $\mathrm{x}=0.60$ is about $190^{\circ} \mathrm{C}$, which is sufficiently high to hold a thermoremanent magnetization.

If titanomagnetite with $\mathrm{x}$ greater than 0.80 were to form when the lava crystallized, it could not acquire a thermoremanent magnetization, since its Curie temperature is below room temperature. Natural remanent magnetization observed with such samples may be a chemical remanent magnetization, acquired during oxidation soon after formation of the rock. This remanence then may not record the geomagnetic field at the exact time of ocean floor spreading (Nagata and Kobayashi, 1963). Low-temperature oxidation of oceanic basalts by warming in zero field (Park and Irving, 1970) has, however, produced magnetic directions in the same direction as the samples had prior to heating. Laboratory experiments by Banerjee (1966) and Senno and Tawara (1967) have suggested the possibility of coupling of the remanences in the formation of a new phase from an original phase. Thus, it is not yet clear what the mechanism of remanence formation would be in titanomagnetites with $\mathrm{x}$ values greater than or close to 0.80 .

Although the formation of titanomagnetites with values of $x \geqslant 0.80$ at the time of crystallization cannot definitely be excluded, our data suggest that they are the products of oxidation. Most values are in the range of 0.60 to 0.70 (average $=0.66$ ), in agreement with a general abundance of $\mathrm{x}$ values $=0.65$ in previous studies (see Johnson and Hall, in press). This, coupled with the hypothetical mechanism of oxidation which includes removal of iron from the lattice to form the red staining in the more oxidized basalts (Johnson and $\mathrm{Hall}$, in press), suggests the mechanism of $\mathrm{Ti}$ enrichment by $\mathrm{Fe}$ removal to produce our observed correlation of greater $\mathrm{x}$ value with greater oxidation (higher $\mathrm{T}_{\mathrm{c}}$.

\section{OPAQUE MICROSCOPY}

Forty-eight polished thin sections were examined (sections were made aboard the Glomar Challenger; ten of them were subsequently repolished on shore). Individual sections do not generally correspond to samples on which thermomagnetic and $\mathrm{Fe} / \mathrm{Ti}$ measurements were made (Table 1). However, observations within the group of sections from each site seem to correlate with the general pattern of thermomagnetic, rock magnetic, and paleomagnetic measurements for that site. The reflected light measurements have been categorized, as best as possible, into the oxidation stages 1 through 5 of Johnson and Hall, (1978).

Most of the observations were made using the Scripps Institution of Oceanography Reichert Microscope with 100-power oil immersion lens and 6.3-power eyepiece. About one-fifth of the samples were later examined at the University of Wyoming, using a Leitz microscope, 100-power oil immersion lens and 12.5-power eyepiece. The size calibration of the Reichert field of view was poorly established, and for that reason there is uncertainty in the numbers quoted for grain size. These numbers should be used only for internal comparison among samples; the absolute value may be inaccurate. Where applicable, estimates of grain size are of effective grain size, and take into account cracking of grains.

Quantification of observations is difficult. We attempted to present the material in tabular form, as given in Table 2. The color of the titanomagnetite grains (for ease of discussion, the oxidized titanomagnetites described herein are referred to simply as "titanomagnetites') ranges from medium brown (MB in Table 2), defined by Hall (personal communication) as the color of unoxidized titanomagnetite, to bright gray-white ( $>\mathrm{GW})$, characteristic of fairly heavily oxidized material. The intermediate colors used in Table 2 are gray-brown (GB), gray (G), and gray-white (GW). Some grains have distinctive brown rims (Rims). Subdivision of the grains by cracking (see Johnson and Hall, 1978) is described in terms of the average number of cracks present per grain. Lightly oxidized grains have zero to one crack per grain; the most heavily oxidized grains observed in these sites generally have six to eight cracks per grain. Relative to other deep-sea basalts examined, these basalts are all fairly unaltered, and correspond at most to a stage 3 or a stage 4 oxidation. Reddish or red-brown staining of the silicates is another indication of the degree of oxidation. Except samples from Holes 410 and $410 \mathrm{~A}$, staining is slight to absent, again indicating a low stage of oxidation.

Description of the grain shape is difficult, because most samples contained several shapes in roughly equal amounts. The following terminology attempts to describe the average shapes observed. "Skeletal" (SK) means grains in the shapes of crosses and fishbone patterns, reflecting preliminary crystallization of the cubic magnetite structure (see grain shapes in Figures 1 and 2, Johnson, in press; fig. 12 and 13b, Johnson and Hall, 1978). "Triangular"' (Tr) is another shape reflecting the cubic structure of magnetite crystals, but "triangular" grains are more equidimensional than "skeletal" grains. Further growth of the grain gives more boxlike equidimensional shapes as completion of the magnetite cubic crystal shape is approached; grains with such shapes are designated squarish (Sq1 and Sq2) in Table 2. They are illustrated by the shapes in fig. 13a of Johnson and Hall (in press) fig. 1, 2, and 5 of Hall et al. (1976), and are similar to fig. 3 of Johnson (in press). Sq1 still suggests the skeletal cross pattern to the observer (shape in fig. 1, Hall et al., 1976); Sq2 has gone to a more square-shaped grain (fig. 5, op. cit.). Still other grains cannot be described in terms of a regular pattern. These subhedral grains are denoted “irregular', (IRR) in Table 2 (fig. 14 of Johnson and Hall, 1978). Certain samples show irregular grains that have very irregular boundaries resembling a "moth-eaten", (Moth) appearance. This is not the same as corroded grain boundaries. We advance no explanation here for that shape. Some samples contain grains too small to see accurately. These are termed dust (Dust), and are frequently disseminated within silicate grains along crystallographic planes. Since cracking in most cases changes the effective grain shape, the dominant grain shape is designated: $\mathrm{E}=$ approximately equidimensional grains and $\mathrm{L}=$ elongate grains. Parentheses are used to indicate additional small component $(<20 \%)$ of another shape. 
TABLE 2

Summary of Microscopic Features of Selected Samples

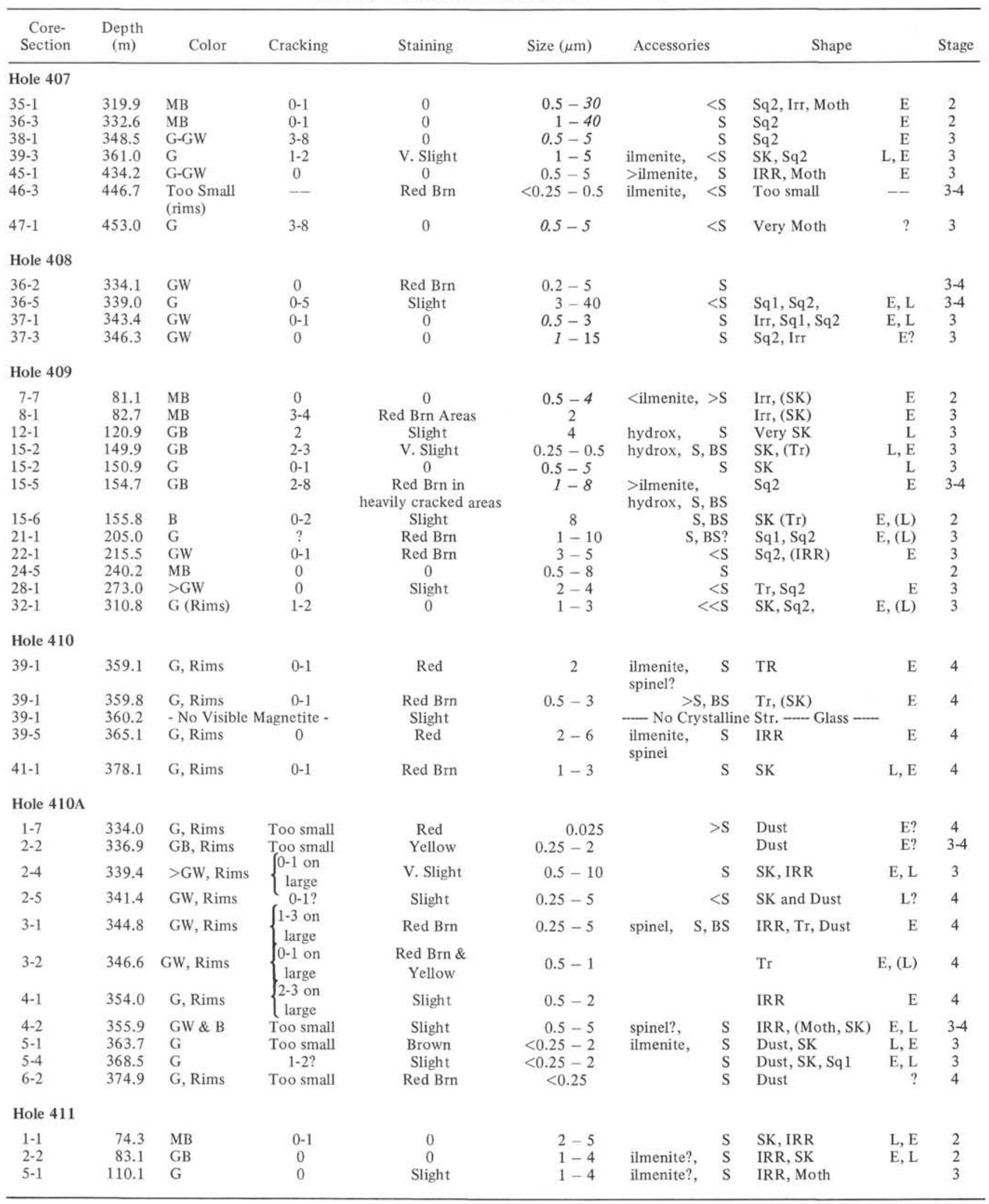


TABLE 2 - Continued

\begin{tabular}{|c|c|c|c|c|c|c|c|c|c|c|}
\hline $\begin{array}{l}\text { Core- } \\
\text { Section }\end{array}$ & $\begin{array}{l}\text { Depth } \\
\text { (m) }\end{array}$ & Color & Cracking & Staining & Size $(\mu \mathrm{m})$ & Accessori & & \multicolumn{2}{|c|}{ Shape } & Stage \\
\hline \multicolumn{11}{|c|}{ Hole $412 \mathrm{~A}$} \\
\hline $\begin{array}{r}1-1 \\
2-2 \\
5-1 \\
7-2 \\
11-3\end{array}$ & $\begin{array}{l}156.3 \\
167.3 \\
194.5 \\
215.1 \\
254.7\end{array}$ & $\begin{array}{l}\text { MB } \\
\text { MB } \\
\text { MB, Rims } \\
\text { MB } \\
\text { MB }\end{array}$ & $\begin{array}{l}0 \\
0-1 \\
0-1 \\
0-1 \\
0-2\end{array}$ & $\begin{array}{c}\text { Slight } \\
0 \\
0 \\
0 \\
0\end{array}$ & $\begin{array}{r}7-15 \\
10-40 \\
5-20 \\
2-15 \\
0.5-5\end{array}$ & >ilmenite, & $\begin{array}{r}>S \\
S \\
S \\
S \\
>S\end{array}$ & $\begin{array}{l}\text { Sq2 } \\
\text { Sq2 } \\
\text { SK, Sq1 } \\
\text { Sq2 } \\
\text { Sq2 }\end{array}$ & $\begin{array}{r}E,(L) \\
E \\
L, E \\
E,(L) \\
E,(L)\end{array}$ & $\begin{array}{l}1-2 \\
1-2 \\
1-2 \\
1-2 \\
1-2\end{array}$ \\
\hline \multicolumn{11}{|l|}{ Hole 413} \\
\hline $1-2$ & 110.4 & GB & 0 & Red Brn & $2-5$ & $\begin{array}{l}\text { >ilmenite, } \\
\text { spinel, }\end{array}$ & S & $\mathrm{Sq} 2, \mathrm{Tr}$ & E & $2-3$ \\
\hline
\end{tabular}

Note: Sizes quoted are only rough estimates of the most abundant grain sizes (see text). In large ranges, the most common size is denoted by italic. In accessory description, $<=$ small amount, $>=$ large amount (as discussed in text). See text for explanation of other symbols.

The main accessory minerals noted are ilmenite, yellow sulfide (S), occasional spinel, and occasional blue sulfide (BS). Ilmenite usually occurs as discrete grains, or very rarely as overgrowths on magnetite, but usually not as lamellae in magnetite. Yellow sulfide is very abundant, and occurs separately, or attached to, or included in magnetite grains. Johnson (in press) has suggested a relationship between Curie temperature (and therefore oxidation stage) and the presence of sulfide grains (see fig. 15, Johnson, 1978). Blue sulfide grains are usually much smaller than yellow sulfide grains, but have the same occurrence habit. Spinel is only occasionally present; when present, it occurs both as separate grains and with magnetite overgrowths. Occasionally, the mammary shape of hydroxides occurs in addition to red-brown staining, and is mentioned in Table 2 (Hydrox). Hematite was not seen in this study. Relative abundance of accessory minerals is indicated by the symbols $>$ and $<$. If an accessory mineral was notably large $(>)$ or small $(<)$ in amount (relative to the other samples examined), it is so indicated.

The most noteworthy observations at each site will be discussed in the following paragraphs. Hole 407 has at least two different petrographic units. The uppermost samples in the hole have much fresher-looking titanomagnetite grains than the ones below. The difference is most strikingly indicated by the brown color of the magnetite in these uppermost samples, as against gray below. The difference is also indicated by the observations that the opaque grains from higher samples are larger and less cracked than their lower counterparts, and contain no ilmenite. This unit appears, from its fresher nature, to be much younger than the underlying units. Indeed, the magnetic polarity of the samples is normal, relative to the reversed ones below, and median destructive fields (MDF) are very much lower than the reversed ones, particularly those reversed ones not apparently having a superimposed secondary normal magnetization. Microscopic observation did not delineate the thermomagnetic boundary in the lower part of the hole (see thermomagnetism discussion).

Site 408 shows a slight difference between the upper two samples and the lower two. The difference is reflected primarily in the reddish staining in the upper flows, and agrees with the observation by petrologists (409 Hole
Summary) that the upper part is more oxidized (and is buff) whereas the lower part is more reduced (blue-gray).

At Site 409, optically fresh and oxidized specimens alternate in a manner similar to the alternation of Curie point value, and of MDF and NRM intensity.

Holes 410 and 410A are striking in their high degree of oxidation and fine grain size. Most specimens contain a fine-grained titanomagnetite with brown rims on all grains. The titanomagnetite is gray to gray-white (occasionally bright gray-white), indicating a high degree of oxidation. In many cases, grains are too small to determine amount of cracking or even grain shape. When cracking is estimated in Table 2, it is on the largest grains and is thus not necessarily representative. All samples have the reddish staining. Spinel is present occasionally, in contrast to other sites.

Opaque mineralogical variations at Site 411 reflect the magnetic divisions indicated by inclination and MDF. Reflected-light microscopy shows the lowermost sample examined to be more oxidized than the ones above (see Table 2). Hole 412A, older than 411, appears from opaque microscopy and thermomagnetism measurements to contain the least oxidized material examined in Leg 49 basalts. All of the titanomagnetite is still medium brown, little cracking is apparent, sulfides are abundant, and grains are large. The one sample from Site 413, just across the fracture zone and older, has a higher degree of oxidation.

We conclude from the observation of opaques in reflected light that, in general, the degree of oxidation predicted by Curie points and examination of opaques is the same for each site or portion of a site. The lesser degree of oxidation tends to be associated with opaques of larger grain size. There is a general lack of high-temperature oxidation in all of these sites. The degree of oxidation is usually low ( 2 to 3 on the stage 1 through 5 scale of Johnson and Hall, 1978), except for the Site 410 holes. There, the grain size of opaques and the high degree of oxidation is consistent with the pillow basalt and tip-of-flow volcanogenic breccia origin proposed in the hole summary (Part 1, this volume) for those holes.

\section{SUMMARY AND CONCLUSION}

Comprehensive investigation of ferromagnetic minerals contained in basalt samples collected on DSDP Leg 49 
(Reykjanes Ridge and northern Mid-Atlantic Ridge traverse), using combined techniques of thermomagnetic measurement, electron microprobe analysis, and reflected light microscopy, suggests the following conclusions:

1) The degree of low-temperature oxidation of titanomagnetite is not necessarily related to the age of the rocks.

2) The degree of low-temperature oxidation does not directly depend upon the sub-bottom depth, either. A 250-meter column of basalt, penetrated in Hole 409, shows samples with alternating degrees of oxidation throughout the hole. The degree of oxidation does depend to a certain extent on lithology.

3) The degree of oxidation is surprisingly low at all of the Leg 49 sites except at Site 410, where the rocks are of breccia and closely related origins.

4) The Curie temperature of the basaltic layer was certainly higher than room temperature and possibly higher than $150^{\circ} \mathrm{C}$ when the rocks initially erupted at the mid-oceanic ridge. Thus, at least the upper $1 \mathrm{~km}$ of oceanic Layer 2 acquired thermoremanent magnetization at the time the layer was formed.

The lack of relationships between oxidation and age or depth suggests that oxidation is probably more influenced by hydrothermal circulation in the basement. Such circulation is probably related to the amount of fracturing of the basement and to the grain size of the basalts. These concepts and the correlation of the magnetochemistry, discussed here, with other rock magnetic properties such as susceptibility, saturation magnetization, and coercive force, as well as with the paleomagnetism results of inclination, intensity, and stability of the natural remanent magnetization, will be discussed in the following article.

\section{ACKNOWLEDGMENTS}

The generous help of Dr. J. M. Hall, Department of Geology, Dalhousie University, in teaching one of the authors (Steiner) the techniques of opaque microscopy, is greatly appreciated.

\section{REFERENCES}

Banerjee, S.K., 1966. Exchange anisotropy in intergrown maghemite and haematite, Geophys. J., v. 10, p. 449-450.

Carmichael, C.M., 1970. The Mid-Atlantic Ridge near $45^{\circ} \mathrm{N}, 7$ Magnetic properties and opaque mineralogy of dredged samples, Canadian J. Earth Sci., v. 7, p. 239.

Hall, J.M., Fink, L.K., and Johnson, H.P., 1976. Petrography of Opaque Minerals, Leg 34. In Hart, S.R., Yeats, R.S., et al., Initial Reports of the Deep Sea Drilling Project, v. 34: 349-362.

Irving, E., Park, J.K., Haggerty, S.E., Aumento, F., and Loncarevic, B., 1970. Magnetism and opaque mineralogy of basalts from the mid-Atlantic ridge at $45^{\circ} \mathrm{N}$, Nature, v. 228 , p. 974.

Johnson, H.P., in press. Opaque mineralogy of the igneous rock samples from Hole 395A - DSDP Leg 45. In Melson, W.G., Rabinowitz, P.D., et al., Initial Reports of the Deep Sea Drilling Project, v. 45: Washington (U.S. Government Printing Office).

Johnson, H.P. and Hall, J.M., 1978. A detailed rock magnetic and opaque mineralogy study of the basalts from the Nazca Plate, Geophys. J. Roy. Astron. Soc., v. 52, p. 45-64.

Nagata, T. and Kobayashi, K., 1963. Thermo-chemical remanent magnetization of rocks, Nature, v. 197, p. 476-477.

Ozima, M. and Sakamoto, N., 1971. Magnetic properties of synthesized titanomaghemite, J. Geophys. Res., v. 76, p. 7035.

Ozima, M., Ozima, M., and Kaneoka, I., 1968. Potassium argon ages and magnetic properties of some dredged submarine basalts and their geophysical implications, J. Geophys. Res., v. 73 , p. 711 .

Park, J.K. and Irving, E., 1970. The Mid-Atlantic Ridge near $45^{\circ} \mathrm{N}$. XII. Coercivity, secondary magnetization, polarity, and thermal stability of dredge samples, Canadian J. Earth Sci., v. 7, p. $1509-1510$.

Readman, P.W. and O'Reilly, W., 1972. Magnetic properties of oxidized (cation-deficient) titanomagnetite, J. Geomag. Geoelect., v. 24 , p. $69-90$.

Senno, H. and Tawara, Y., 1967. Exchange Anisotropy in the mixed phse of $\gamma-\mathrm{Fe}_{2} \mathrm{O}_{3}$ and $\alpha-\mathrm{Fe}_{2} \mathrm{O}_{3}$, Japanese J. Applied Phys., v. 6, p. 509-511. 